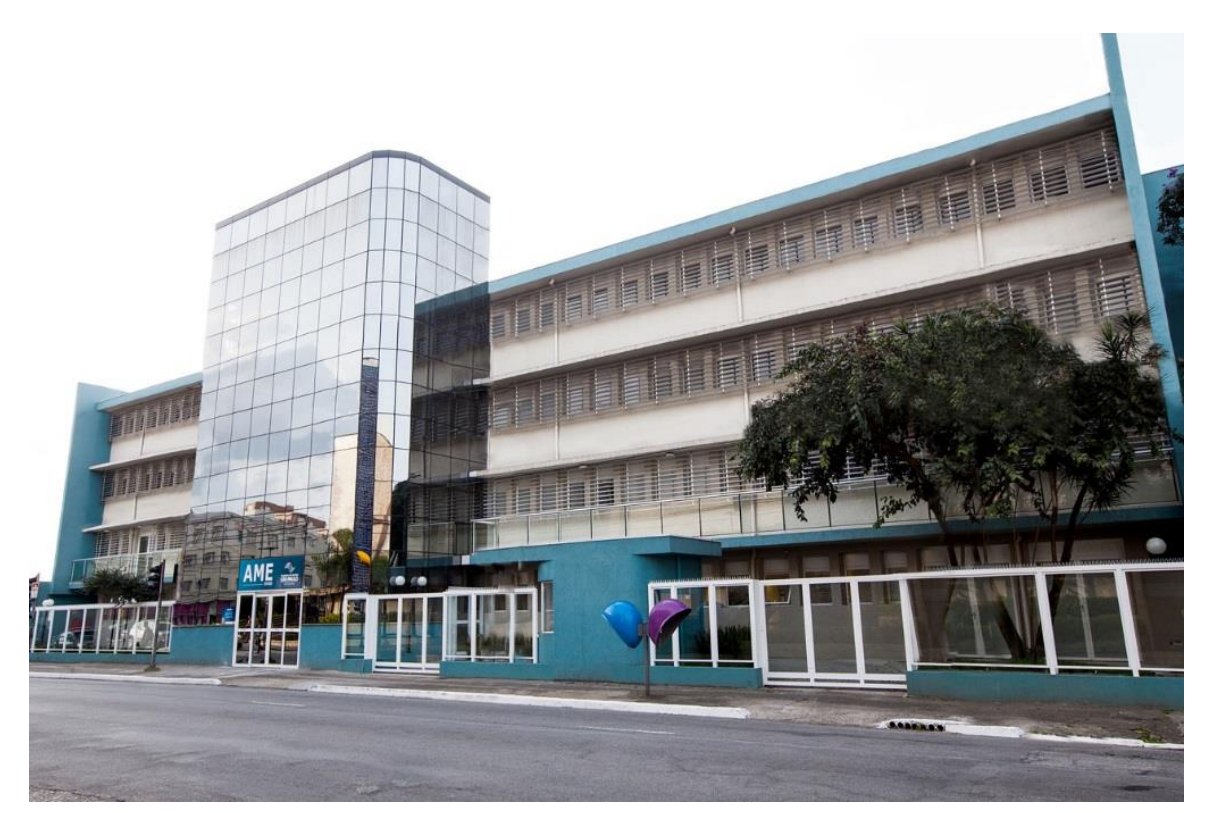

\title{
MONITORAMENTO DE CASOS - OLHAR INTEGRAL DA ADMISSÃO A ALTA, ORGANIZAÇÃO DO TRABALHO DOS ENFERMEIROS EM UNIDADE AMBULATORIAL
}

Joana D’arc Ricardo dos Santos, Andrea Aparecida da Fonseca Monteiro, Eduardo Canteiro Cruz e Marcia Maiumi Fukujima

\section{INTRODUÇÃO}

Monitorar pacientes inseridos na linha de cuidado institucional é um processo importante, que resulta em dados que contribuirão para melhoria continua, além de favorecer a troca de informações e a comunicação entre as equipes envolvidas na assistência ao paciente. Seguindo essa linha de pensamento foi elaborado modelo de dimensionamento da equipe de enfermeiros inseridos na linha de cuidados para a gestão dos casos dos pacientes em unidade ambulatorial especializada no atendimento a idosos.

OBJETIVO: classificar os casos, de acordo protocolo de classificação institucional e acompanhar o desfecho, direcionando e discutindo com os profissionais envolvidos no processo para elucidação diagnostica e conduta dentro dos prazos estabelecidos.

\section{DESENVOLVIMENTO}

Com a implantação do processo de monitoramento dos casos, foi definido o enfermeiro como gestor do cuidado, profissional responsável pelo monitoramento dos casos.

Após, foi realizado o redimensionamento do quadro de enfermeiros de forma a atender a demanda de pacientes, treinamento sobre o protocolo institucional e organização das agendas de consultas e exames de forma a atender os prazos do protocolo institucional.

Os pacientes admitidos recebem orientação sobre o modelo de atendimento que esta inserido, os dados são alimentados em painel Excel sob responsabilidade do enfermeiro da linha de cuidado para acompanhamento, e organização dos dados.

\section{RESULTADOS}

No período de abril de 2017 a setembro de 2018 totalizamos 4075 pacientes inseridos neste processo, identificado 0,83\% dos pacientes monitorados evoluíram a óbito, $0,36 \%$ foram identificados como casos oncológicos, internações recentes foram incluídas como critério para classificação de alto risco e médico risco a partir do 3 bimestre de 2018 e totalizaram $4 \%$ do atendimento :

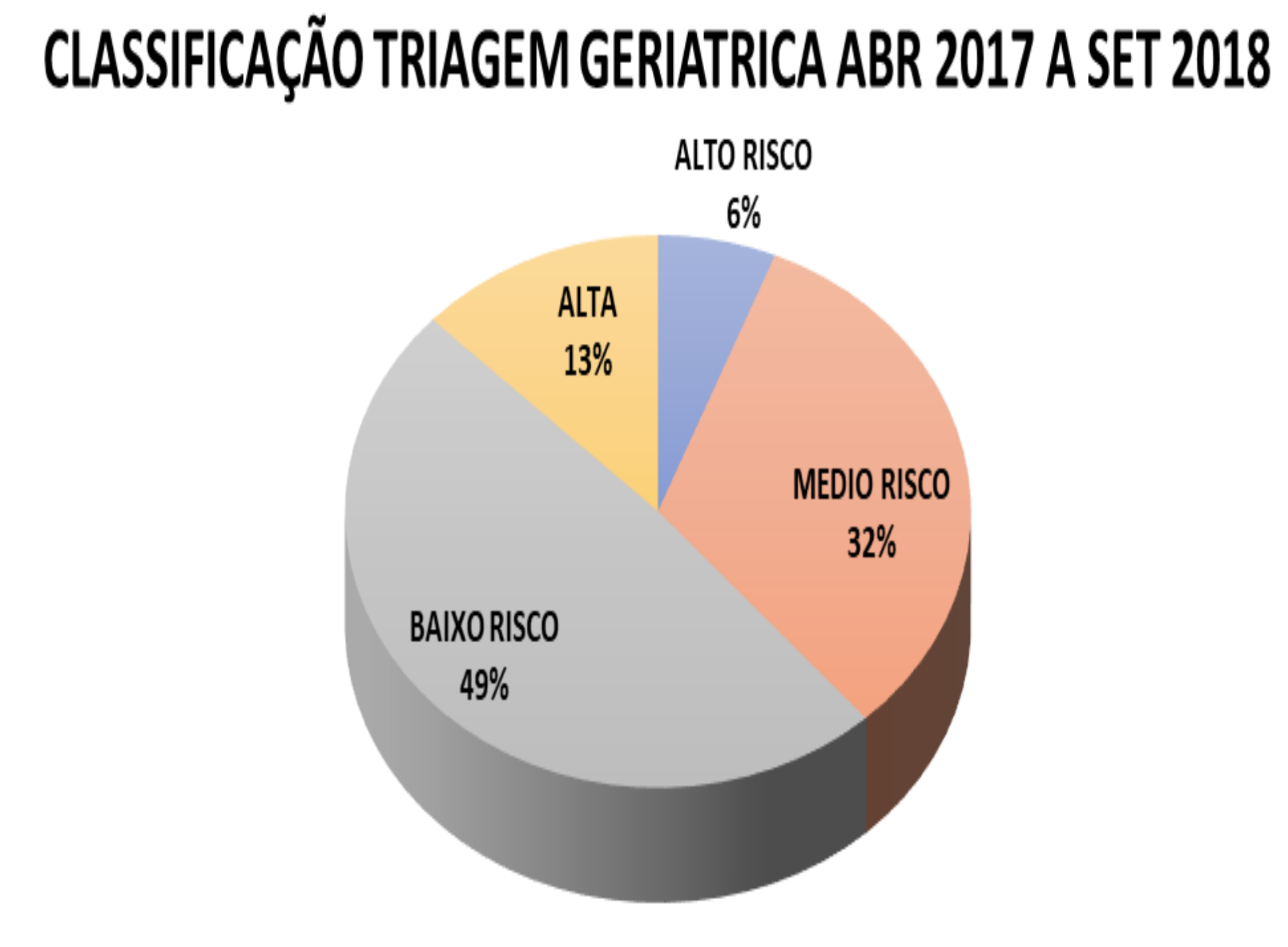

\section{Lições aprendidas:}

O dimensionamento dos profissionais para acompanhamento dos casos gerou resultados importantes para elaborar e alinhar o processo de trabalho institucional, permitindo analisar a atuação dos enfermeiros no monitoramento, favorecendo as discussões clinicas e a interação das equipes multiprofissionais.

Palavras chave: Palavras chaves: monitoramento, enfermeiro e dimensionamento.

CLASSIFICAÇÃO TRIAGEM GERIATRICA ABR 2017 A SET 2018

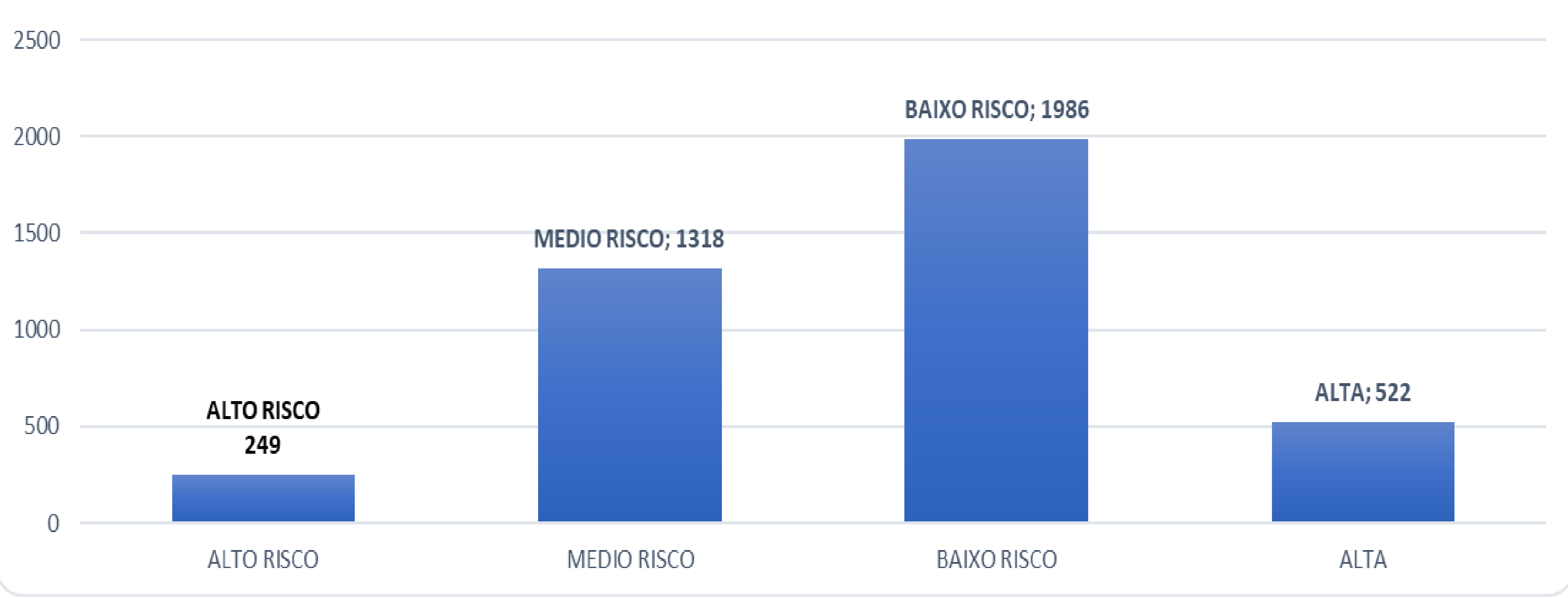

